\title{
Internet-based cohort study of HIV testing over 1 year among men who have sex with men living in England and exposed to a social marketing intervention promoting testing
}

\author{
Ford Hickson, ${ }^{1}$ Keith Tomlin, ${ }^{1}$ James Hargreaves, ${ }^{1}$ Chris Bonell, ${ }^{2}$ David Reid, ${ }^{1}$ \\ Peter Weatherburn ${ }^{1}$
}

- Additional material is

published online only. To view please visit the journal online (http://dx.doi.org/10.1136/ sextrans-2014-051598).

${ }^{1}$ London School of Hygiene \& Tropical Medicine, London, UK ${ }^{2}$ Institute of Education, London, UK

\section{Correspondence to} Dr Ford Hickson, Sigma Research, Department of Social \& Environmental Health Research, London School of Hygiene \& Tropical Medicine, 15-17 Tavistock Place, London WC1H 9SH, UK;

ford.hickson@|shtm.ac.uk

Received 21 March 2014 Revised 7 July 2014 Accepted 8 September 2014 Published Online First 30 September 2014

\section{CrossMark}

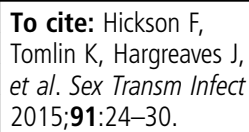

\section{ABSTRACT}

Objectives Increasing HIV testing among men who have sex with men (MSM) is a major policy goal in the UK. Social marketing is a common intervention to increase testing uptake. We used an online panel of MSM to examine rates of HIV testing behaviour and the impact of a social marketing intervention on them.

Method MSM in England were recruited to a longitudinal internet panel through community websites and a previous survey. Following an enrolment survey, respondents were invited to self-complete 13 surveys at monthly intervals throughout 2011. A unique alphanumeric code linked surveys for individuals. Rates of HIV testing were compared relative to prompted recognition of a multi-part media campaign aiming to normalise HIV testing.

Results Of 3386 unique enrolments, 2047 respondents were included in the analysis, between them submitting 15353 monthly surveys (equivalent to 1279 years of follow-up), and recording 1517 HIV tests taken, giving an annual rate of tests per participant of $1.19(95 \% \mathrm{Cl}$ 1.13 to 1.25$)$. Tests were highly clustered in individuals (61\% reported no test during the study). Testing rates were higher in London, single men and those aged 25-34 years. Only $7.6 \%$ recognised the intervention when prompted. After controlling for sociodemographic characteristics and exposure to other health promotion campaigns, intervention recognition was not associated with increased likelihood of testing. Higher rates of testing were strongly associated with higher number of casual sexual partners and how recently men had HIV tested before study enrolment.

Conclusions This social marketing intervention was not associated with increased rates of HIV testing. More effective promotion of HIV testing is needed among MSM in England to reduce the average duration of undiagnosed infection.

\section{INTRODUCTION}

Increasing HIV testing in at-risk populations is a major policy goal in England. Late diagnosis is the major cause of HIV mortality, while early diagnosis and treatment also reduces infectiousness. Knowledge and discussion of HIV statuses can inform couples' sexual decision-making, and aggregate sexual risk-taking declines among HIV-positive people following HIV diagnosis. ${ }^{1}$
The UK has a high prevalence of HIV among men who have sex with men (MSM), ${ }^{2}$ and approximately one-third of HIV diagnosed among MSM in the UK is late. ${ }^{3}$ Over many years, England has had various national HIV health promotion media interventions targeting MSM about HIV/sexually transmitted infections testing (Think, Talk, Time to Test?, 1997; See To It, 1998; Promoting Testing, 2009) and undiagnosed HIV infection (Assume Nothing, 1997; What's on Your Mind, 1998; Better off Knowing, 1999; Think Again, 2003; Undiagnosed Infection, 2008). Evidence for the behavioural impact of media campaigns on HIV testing among MSM is weak. $^{4}$ UK policy now recommends all MSM HIV-test at least annually and more frequently if having unprotected anal intercourse with multiple partners. ${ }^{3}$ Healthcare providers are recommended to routinely offer HIV testing to all MSM at least annually or more frequently if clinical symptoms are suggestive of HIV seroconversion or they have ongoing high-risk exposure. ${ }^{5}$

We undertook a longitudinal observational study of MSM using monthly internet-based surveys over 1 year. We examined patterns of HIV testing and assessed whether testing was associated with individual exposure to an intervention designed to increase HIV testing and whether rates of testing were higher during periods when the intervention was delivered. Our sample, like nearly all research with MSM, involves convenience samples because there is no overall sampling frame for this population. MSM recruited via the internet engage in higher sexual risk than MSM overall, ${ }^{6}$ but appear more demographically representative than community or clinic samples. ${ }^{7} 8$

\section{METHODS}

We recruited MSM via the internet. An enrolment survey (month 0 ) was followed by 13 monthly secure online surveys (months 1-13) hosted by Demographix. Enrolment was open for 8 weeks (20 December 2010-2014 February 2011). No sample size calculation was performed as this was an exploratory study using a method not previously used. Inclusion criteria were: male; England resident; aged 16 years or above; sexually attracted to/ has sex with men; can supply an email address.

Invitations to enrol were sent to men who had completed an earlier 2010 survey $^{9}$ and to users of 
two gay-dating websites, ManHunt and Gaydar. Advertising was carried by Gaydar and in email bulletins by NAM and the Lesbian and Gay Foundation.

Potential participants were informed at enrolment of the survey aims and methods and asked to consent to provide online data, including that relating to sexual activity and HIV testing. Participants provided an email address which was linked to a unique alphanumeric code. Emails were stored separately from data. Names, addresses and post codes were not requested. Before analysis, email addresses were examined for uniqueness and where duplicate submissions were made, the second submission was deleted.

Enrolment questions covered sociodemographic data (age, ethnicity, sexual identity, local authority of residence, education level, employment, income, household composition, relationship status). Local authority of residence was grouped into corresponding Strategic Health Authorities (SHA).

Enrolment was followed by 13 surveys sent on the first day of each month covering events in the previous calendar month.

In two surveys, we collected data on recognition of three HIV health promotion interventions delivered in England over the study period. 'I Did It' was delivered by Terrence Higgins Trust (THT) with the aim of increasing HIV testing by making MSM aware of its ease and convenience. It comprised three image/text media advertisements, a short radio advertisement and a website implemented from December 2010 to April 2011. Because the website was aimed both at men who had already tested and those who might, its use is not examined here.

Two other media interventions, 'Clever Dick/Smart Arse' and 'Count Me In', delivered respectively by THT and GMFA, were used to assess men's propensity for exposure to HIV health promotion, hypothesised as a potential confounder. 'Clever Dick/ Smart Arse' aimed to promote condom use (November 2011February 2012), 'Count Me In' encouraged men to commit to a five-step action plan including, but not limited to HIV testing. We regarded potential exposure to this longer-term intervention to be constant throughout the study period. Recognition of 'I Did It' was assessed in month 7 (August 2011) and of 'Clever Dick/Smart Arse' and 'Count Me In' in month 13 (January 2012).

Data on lifetime sexual partnerships and most recent prestudy HIV test were collected at month 1 . Each month, participants were asked if they had tested for HIV in the previous month and, if so, the result. Participants already diagnosed as HIV-positive on entry were excluded from analyses, as were those providing no or inconsistent HIV test results.

After assessing cohort recruitment and retention at each month, we described participants' sociodemographic characteristics, prior HIV testing, sexual behaviour and exposure to the interventions among participants who completed months 1, 7 and 13 . We then calculated rates of HIV testing. Each completed questionnaire represented a month of follow-up (ie, each calendar month was treated as a period of exposure in which a test could have happened). Only survey points in which the HIV testing question had been answered were included in analysis. No data were imputed as no assumptions were made about panel members' HIV testing activity in the months they did not report. Where a questionnaire was not completed for a given month, that month was censored, not contributing to total follow-up time. Participants joining the study as HIV-negative or untested and diagnosed as HIV-positive during the study period did not contribute follow-up time after reporting their diagnosis, with the month of the positive result contributing 2 weeks' follow-up. Participants reporting HIV-negative results continued to have their follow-up time included. For untested participants, their last month reporting this and all prior follow-up time was included in the analysis. We calculated HIV testing rates, CIs and unadjusted rate ratios using Poisson regression adjusted for individual-level random effects to account for multiple followups. We next examined HIV testing rates and rate ratios across demographic subgroups. Then, we assessed whether individual exposure to the 'I Did It' intervention was associated with HIV testing after adjusting for potential confounders. We used random effects Poisson regression to adjust the rate ratio for exposure to the 'I Did It' press advertisement. We adjusted for other exposures separately, and those exposures which seemed potential confounders were included in three models: the first included awareness of the 'I Did It' intervention and sociodemographic variables associated with rates of testing; the second added numbers of sexual partnerships and previous HIV testing and the third added awareness of the other interventions.

Finally, we divided the study duration into three 'exposure periods': period 1 (1 January 2011-30 April 2011) when 'I Did It' was active; period 2 (1 May 2011-30 September 2011) when neither 'I Did It' nor 'Clever Dick/Smart Arse' were active and period 3 (1 October 2011-31 January 2012) when 'Clever Dick/Smart Arse' were implemented. Potential exposure to 'Count Me In' was regarded as constant throughout.

A fuller description of the methods (online supplementary file 1) and the survey tools (online supplementary files 2, 3 and 4) relevant to this paper are supplied as web-only files.

The study was approved by London School of Hygiene and Tropical Medicine Ethics Committee (reference 5834).

\section{RESULTS}

Following removal of 30 non-qualifying submissions and 103 duplicate submissions, there were 3386 enrolments of whom $45 \%$ had previously taken part in the European MSM Internet Survey. Over the 13 months of the survey, a monthly mean of $53.6 \%$ of enrolees opened the invitation and a mean of $88.4 \%$ of those who opened the survey submitted it. No subsequent surveys were completed by 827 (24.4\%); 57 $(1.7 \%)$ completed a subsequent survey but gave no or inconsistent HIV status data and 455 (13.4\%) were HIV-positive on joining the survey. These groups were excluded from subsequent analyses, giving a main analysis sample of 2047 participants (see figure 1, a flow-chart of the procedure provided as a web-only file).

In the main sample, 1966 participants gave answers to all the sociodemographic characteristics. Table 1 displays these. Over half were aged below 45 years and most defined themselves as ethnically white and as gay or bisexual. The largest proportions lived in London (31.2\%), the smallest proportions in the North East (3.4\%). Almost half had higher education and most were employed. Differences in the profile of non-responders and responders were similar for declining to supply an email address during enrolment and for not returning surveys once enrolled. Compared with men who submitted the first survey, enrolees who did not submit month 1 survey data were younger, less highly educated, less likely to be out about their homosexuality and more likely to be bisexual, members of ethnic minorities and living in the North of England (data not shown).

Subgroup 1 comprised 1122 individuals who submitted the month 7 survey and thereby answered the question relating to 'I Did It'. In subgroup 1, 86 participants (7.6\%) reported that they recognised or had read the 'I Did It' print advertisement and 1036 (91.9\%) reported that they did not recognise the advertisement (table 1). 
Table 1 Rates of HIV testing, and unadjusted and adjusted rate ratios, by sociodemographic exposure

\begin{tabular}{|c|c|c|c|c|c|c|c|}
\hline & No of men (n) & No of men (\%) & No of HIV tests & Person/years & Rate of HIV testing & $\begin{array}{l}\text { Unadjusted rate } \\
\text { ratio }(95 \% \mathrm{Cl})^{*}\end{array}$ & $\begin{array}{l}\text { Adjusted rate } \\
\text { ratio }(95 \% \mathrm{Cl}) \\
\mathrm{n}=1966\end{array}$ \\
\hline All participants & 2047 & 100.0 & 1517 & 1279.4 & 1.19 & - & - \\
\hline Age group (years) & & & & & & $\mathrm{p}=0.003$ & $\mathrm{p}=0.06$ \\
\hline$<25$ & 175 & 8.6 & 103 & 96.1 & 1.07 & Ref & Ref \\
\hline $25-34$ & 449 & 21.9 & 373 & 248.6 & 1.50 & 1.36 (1.01 to 1.82$)$ & 1.42 (1.02 to 1.97$)$ \\
\hline $35-44$ & 555 & 27.1 & 432 & 348.8 & 1.24 & 1.13 (0.85 to 1.51$)$ & 1.18 (0.84 to 1.66$)$ \\
\hline $45-54$ & 526 & 25.7 & 385 & 348.1 & 1.11 & 1.01 (0.75 to 1.35 ) & 1.16 (0.82 to 1.64$)$ \\
\hline $55+$ & 332 & 16.2 & 221 & 234.2 & 0.94 & 0.88 (0.64 to 1.20$)$ & $1.02(0.69$ to 1.50$)$ \\
\hline Missing & 10 & 0.5 & 3 & 3.6 & 0.84 & - & - \\
\hline Ethnic group & & & & & & $p=0.0003$ & $\mathrm{p}=0.19$ \\
\hline White British & 1,672 & 81.7 & 1142 & & 1.09 & Ref & Ref \\
\hline White other & 254 & 12.4 & 242 & 160.6 & 1.51 & 1.40 (1.14 to 1.71$)$ & 1.20 (0.97 to 1.47$)$ \\
\hline Black & 26 & 1.3 & 29 & 15.1 & 1.92 & 1.67 (0.95 to 2.93 ) & 1.39 (0.80 to 2.43$)$ \\
\hline Asian & 50 & 2.4 & 54 & 29.5 & 1.83 & 1.61 (1.06 to 2.43 ) & 1.21 (0.79 to 1.86$)$ \\
\hline Other & 27 & 1.3 & 36 & 17.3 & 2.08 & 1.79 (1.06 to 3.03$)$ & 1.50 (0.89 to 2.53$)$ \\
\hline Missing & 18 & 0.9 & 14 & 9.4 & 1.49 & - & - \\
\hline Sexual identity & & & & & & $p=0.47$ & \\
\hline Gay/homosexual & 1,709 & 83.5 & 1275 & & 1.19 & Ref & Not included \\
\hline Bisexual & 171 & 8.3 & 118 & 106.1 & 1.11 & 0.89 (0.69 to 1.15$)$ & in multivariate \\
\hline Other & 149 & 7.3 & 119 & 90.4 & 1.32 & 1.11 (0.85 to 1.45$)$ & Model \\
\hline Missing & 18 & 0.9 & 5 & 9.3 & 0.56 & - & \\
\hline SHA of residence & & & & & & $p=0.0001$ & $p=0.01$ \\
\hline London & 638 & 31.2 & 605 & 404.3 & 1.50 & Ref & Ref \\
\hline South West & 183 & 8.9 & 131 & 117.9 & 1.11 & 0.75 (0.58 to 0.97 ) & 0.84 (0.65 to 1.10$)$ \\
\hline South Central & 138 & 6.8 & 97 & 93.0 & 1.04 & 0.71 (0.53 to 0.95$)$ & 0.79 (0.58 to 1.06$)$ \\
\hline South East coast & 187 & 9.1 & 108 & 119.2 & 0.91 & 0.60 (0.45 to 0.78 ) & 0.66 (0.50 to 0.87$)$ \\
\hline East of England & 152 & 7.4 & 107 & 93.3 & 1.15 & 0.75 (0.57 to 1.00$)$ & $0.83(0.63$ to 1.11$)$ \\
\hline East Midlands & 129 & 6.3 & 63 & 80.5 & 0.78 & 0.52 (0.37 to 0.72$)$ & 0.56 (0.40 to 0.78$)$ \\
\hline West Midlands & 135 & 6.6 & 74 & 83.5 & 0.89 & 0.62 (0.45 to 0.86$)$ & 0.68 (0.49 to 0.93$)$ \\
\hline Yorkshire \& Humber & 145 & 7.1 & 91 & 86.3 & 1.05 & 0.68 (0.51 to 0.92$)$ & 0.70 (0.51 to 0.95$)$ \\
\hline North West & 219 & 10.7 & 165 & 129.0 & 1.28 & 0.82 (0.64 to 1.04$)$ & 0.89 (0.69 to 1.14$)$ \\
\hline North East & 70 & 3.4 & 39 & 40.5 & 0.96 & 0.66 (0.43 to 1.01$)$ & 0.77 (0.50 to 1.18$)$ \\
\hline Missing & 51 & 2.5 & 37 & 31.9 & 1.16 & - & - \\
\hline Highest educational qualification & & & & & & $\mathrm{p}=0.87$ & \\
\hline Left education $<16$ years & 350 & 17.1 & 225 & 197.1 & 1.14 & Ref & Not included \\
\hline Completed secondary education & 679 & 33.2 & 465 & 402.2 & 1.16 & 0.99 (0.79 to 1.23$)$ & in multivariate \\
\hline Higher education & 1,001 & 48.9 & 820 & 672.1 & 1.23 & 1.03 (0.84 to 1.26$)$ & Model \\
\hline Missing & 17 & 0.8 & 7 & 7.9 & 0.88 & - & \\
\hline Occupation & & & & & & $p=0.11$ & $\mathrm{p}=0.83$ \\
\hline Employed full/part-time & 1,588 & 77.6 & 1185 & 987.9 & 1.20 & Ref & Ref \\
\hline Unemployed & 99 & 4.9 & 76 & 60.1 & 1.26 & 1.10 (0.79 to 1.52 ) & 1.01 (0.69 to 1.47$)$ \\
\hline Student & 107 & 5.2 & 94 & 62.5 & 1.50 & 1.24 (0.92 to 1.69$)$ & 1.16 (0.80 to 1.68$)$ \\
\hline Other & 236 & 11.5 & 152 & 161.7 & 0.94 & 0.81 (0.65 to 1.02 ) & 0.94 (0.73 to 1.22$)$ \\
\hline Missing & 17 & 0.8 & 10 & 7.3 & 1.38 & - & - \\
\hline Gross income per year (f) & & & & & & $p=0.10$ & $p=0.16$ \\
\hline$<10000$ & 262 & 12.8 & 207 & 160.9 & 1.29 & Ref & Ref \\
\hline 10 000-39999 & 1,179 & 57.6 & 800 & 725.2 & 1.10 & 0.83 (0.67 to 1.03 ) & 0.82 (0.62 to 1.07$)$ \\
\hline$\geq 40000$ & 461 & 22.5 & 400 & 304.3 & 1.31 & 1.00 (0.79 to 1.27$)$ & $0.97(0.71$ to 1.31$)$ \\
\hline Unwilling to answer & 132 & 6.5 & 106 & 83.9 & 1.26 & 0.93 (0.67 to 1.30$)$ & 0.92 (0.64 to 1.32$)$ \\
\hline Missing & 13 & 0.6 & 4 & 5.1 & 0.79 & - & - \\
\hline Household composition & & & & & & $p=0.06$ & $\mathrm{p}=0.83$ \\
\hline Lives alone & 787 & 38.5 & 581 & 493.7 & 1.18 & Ref & Ref \\
\hline Lives with a partner & 692 & 33.8 & 481 & 443.9 & 1.08 & 0.90 (0.76 to 1.07 ) & 1.04 (0.82 to 1.32$)$ \\
\hline Lives with others (not a partner) & 551 & 26.9 & 448 & 332.0 & 1.35 & 1.12 (0.94 to 1.34$)$ & $1.06(0.88$ to 1.29$)$ \\
\hline Missing & 17 & 0.8 & 7 & 9.8 & 0.72 & - & - \\
\hline Relationship status & & & & & & $\mathrm{p}=0.008$ & $\mathrm{p}=0.03$ \\
\hline Single & 1,065 & 52.0 & 829 & 648.0 & 1.28 & Ref & Ref \\
\hline With one man only & 784 & 38.3 & 526 & 499.5 & 1.05 & 0.81 (0.70 to 0.94$)$ & 0.81 (0.65 to 1.01$)$ \\
\hline
\end{tabular}


Table 1 Continued

\begin{tabular}{|c|c|c|c|c|c|c|c|}
\hline & No of men (n) & No of men $(\%)$ & No of HIV tests & Person/years & Rate of HIV testing & $\begin{array}{l}\text { Unadjusted rate } \\
\text { ratio }(95 \% \mathrm{Cl})^{*}\end{array}$ & $\begin{array}{l}\text { Adjusted rate } \\
\text { ratio }(95 \% \mathrm{Cl}) \\
\mathrm{n}=1966\end{array}$ \\
\hline With $2+$ men but no women & 64 & 3.2 & 73 & 46.4 & 1.57 & 1.26 (0.88 to 1.82$)$ & 1.36 (0.93 to 1.99$)$ \\
\hline With one or more women & 117 & 5.7 & 78 & 76.4 & 1.02 & $0.76(0.56$ to 1.05$)$ & 0.89 (0.60 to 1.31$)$ \\
\hline Missing & 17 & 0.8 & 11 & 9.0 & 1.22 & - & - \\
\hline
\end{tabular}

*Population excludes those with missing data within each exposure.

SHA, Strategic Health Authorities.

Subgroup 2 included 879 participants who also submitted the month 1 survey and, thereby, gave answers to questions about the lifetime number of sexual partners and the most recent HIV test prior to joining the survey. In subgroup 2, 291 participants $(32.8 \%)$ reported an average of fewer than one casual sexual partner per month, while $236(26.6 \%)$ reported more than two casual partners per month. The median number of lifetime sexual partners was 90 (IQR 25-300). Being tested in the month before enrolment was reported by 109 participants (12.3\%), while $232(26.2 \%)$ had last tested more than 12 months before enrolment. Of those who submitted the month 1 survey, 158 (17.8\%) had never had an HIV test.

Finally, subgroup 3 included 719 participants who also submitted the month 13 survey and, thereby, answered questions about awareness of the 'Clever Dick/Smart Arse' and 'Count Me In' interventions. In subgroup 3, 246 participants (34.2\%) had

Table 2 Rates of HIV testing and unadjusted rate ratios for exposures measured in each subgroup

\begin{tabular}{|c|c|c|c|c|c|c|}
\hline & No of men (n) & No of men (\%) & No of HIV tests & Person/years & Rate of HIV testing & $\begin{array}{l}\text { Unadjusted rate } \\
\text { ratio }(95 \% \mathrm{Cl})^{*}\end{array}$ \\
\hline \multicolumn{7}{|c|}{ Subgroup 1 ( $n=1127$ ) completed month 7 (incl. 'I Did It' measures) } \\
\hline 'I Did It' press advertisement & & & & & & $p=0.03$ \\
\hline Not seen advertisement & 1036 & 91.9 & 1044 & 874.8 & 1.19 & Ref \\
\hline Recognised, or had seen and read, advertisement & 86 & 7.6 & 125 & 74.9 & 1.67 & 1.37 (1.03 to 1.81$)$ \\
\hline Missing & 5 & 0.5 & 9 & 3.3 & 2.73 & - \\
\hline \multicolumn{7}{|c|}{ Subgroup 2 ( $n=887$ ). Also completed month 1 (incl. sexual partners and prepanel HIV testing) } \\
\hline Lifetime sexual partners & & & & & & $p=0.09$ \\
\hline$\leq 20$ & 193 & 21.8 & 177 & 172.5 & 1.03 & Ref \\
\hline $21-50$ & 171 & 19.3 & 171 & 150.5 & 1.14 & $1.08(0.81$ to 1.44$)$ \\
\hline $51-100$ & 141 & 15.9 & 157 & 125.6 & 1.25 & $1.21(0.90$ to 1.62$)$ \\
\hline $101-250$ & 130 & 14.7 & 166 & 113.6 & 1.46 & $1.41(1.04$ to 1.90$)$ \\
\hline $251-500$ & 119 & 13.4 & 136 & 107.7 & 1.26 & $1.22(0.89$ to 1.66$)$ \\
\hline $500+$ & 128 & 14.4 & 175 & 114.7 & 1.52 & $1.48(1.10$ to 1.99$)$ \\
\hline Missing & 5 & 0.6 & 7 & 4.9 & 1.42 & - \\
\hline Monthly average casual sexual partners & & & & & & $\mathrm{p}<0.0001$ \\
\hline$<1$ & 291 & 32.8 & 199 & 259.0 & 0.77 & Ref \\
\hline $1-2$ & 360 & 40.6 & 410 & 320.1 & 1.28 & 1.67 (1.34 to 2.07$)$ \\
\hline$>2$ & 236 & 26.6 & 380 & 210.3 & 1.81 & 2.32 (1.85 to 2.92$)$ \\
\hline Missing & 0 & 0 & 0 & 0 & 0 & - \\
\hline Last HIV test before survey enrolment & & & & & & $\mathrm{p}<0.0001$ \\
\hline Never tested & 158 & 17.8 & 58 & 156.8 & 0.37 & Ref \\
\hline$>12$ months before enrolment & 232 & 26.2 & 109 & 198.4 & 0.55 & $1.48(1.06$ to 2.07$)$ \\
\hline 6-12 months before enrolment & 122 & 13.8 & 126 & 109.4 & 1.15 & $3.12(2.24$ to 4.35$)$ \\
\hline $1-6$ months before enrolment & 263 & 29.7 & 370 & 225.7 & 1.64 & 4.42 (3.30 to 5.92$)$ \\
\hline$<1$ month before enrolment & 109 & 12.3 & 323 & 97.0 & 3.33 & 9.01 (6.65 to 12.20$)$ \\
\hline Missing & 3 & 0.3 & 3 & 1.9 & 1.57 & - \\
\hline \multicolumn{7}{|c|}{ Subgroup 3 ( $n=719$ ). Also completed month 13 (incl. 'Clever Dick' and 'Count Me In' measures) } \\
\hline 'Clever Dick/Smart Arse' press advertisements & & & & & & $p=0.11$ \\
\hline No awareness of advertisements & 473 & 65.8 & 531 & 446.6 & 1.19 & Ref \\
\hline Any awareness of advertisements & 246 & 34.2 & 329 & 233.7 & 1.41 & $1.18(0.96$ to 1.44$)$ \\
\hline 'Count Me In' intervention & & & & & & $p=0.0006$ \\
\hline No awareness of intervention & 500 & 69.5 & 532 & 475.8 & 1.12 & Ref \\
\hline Any awareness of intervention & 219 & 30.5 & 328 & 204.5 & 1.60 & $1.43(1.17$ to 1.75$)$ \\
\hline Time period of testing & & & & & & $p=0.21$ \\
\hline 1 January 2011-30 April 2011 & 719 & 100.0 & 283 & 223.1 & 1.27 & Ref \\
\hline 1 May 2011-30 September 2011 & 719 & 100.0 & 274 & 236.1 & 1.16 & $0.93(0.79$ to 1.10 \\
\hline 1 October 2011-31 January 2013 & 719 & 100.0 & 303 & 211.1 & 1.37 & $1.08(0.92$ to 1.27$)$ \\
\hline
\end{tabular}

*Population excludes those with missing data within each exposure. 
some awareness of the THT 'Clever Dick/Smart Arse' print campaign to promote condom use and 219 (30.5\%) had some awareness of 'Count Me In'.

The 2047 participants in the main sample submitted a total of 15353 monthly surveys (range 1-13 per participant), with a total follow-up time of 1279.4 person-years (mean of 0.63 years per participant). Participants reported 1517 HIV tests giving an annual rate of 1.19 tests per participant (95\% CI 1.13 to 1.25 ). The number of tests per participant ranged from zero to 10 . Testing was strongly clustered: 1246 participants (60.9\%) reported no tests during the study, while 39 participants reported having 5-10 tests during follow-up; 1647 participants $(80.5 \%)$ had already received a negative HIV test result prior to joining the survey, while 400 (19.5\%) had never been tested. Among those who joined as untested, 382 submitted at least one further survey, of whom 78 (20.0\%) reported having their first test. Eighteen participants reported testing HIV-positive during the course of the survey $(0.88 \%$ of enrollers, an annual diagnosis incidence of $1.4 \%$ ).

At the univariate level age, ethnicity, SHA of residence and relationship status were strongly associated with HIV testing (table 2) status which remained significant ( $p=0.01, p=0.03$, respectively) after adjustment. Men living in Yorkshire \& Humber, East Midlands, West Midlands and the South East Coast had the lowest rates of testing. Men in a relationship with one other man were less likely to test than single men (rate ratio $0.81,95 \%$ CI 0.65 to 1.01 ).

The rate of testing among those who recognised or had read the 'I Did It' press advertisement was 1.67, compared with 1.19 in those who did not recognise the advertisement, giving an unadjusted rate ratio of 1.37 (95\% CI 1.03 to $1.81, \mathrm{p}=0.03$, table 2). However, after adjusting for age-group, SHA of residence and relationship status, the association between awareness of the 'I Did It' advertisement and testing was weakened (rate ratio $1.29,95 \%$ CI 0.97 to $1.70, \mathrm{p}=0.08$, table 3 ).

Participants with a monthly average of two or more casual sexual partners had a higher unadjusted rate of HIV testing than those reporting a monthly average of $<1$ (rate ratio $2.32,95 \%$ CI 1.85 to $2.92, \mathrm{p}<0.0001)$. Participants who had tested in the month prior to the panel had a rate of testing nine times higher than those who had never tested (rate ratio 9.01, 95\% CI 6.65 to $12.20, \mathrm{p}<0.0001)$, with a trend between time since the last test and rate of testing during it ( $p$ for trend $<0.0001$ ). A weaker unadjusted association was present between lifetime number of sexual partners and testing during the survey $(p=0.09)$.

Patterns of HIV testing in subgroup 2 were similar to subgroup 1. Further adjustment for sexual partners and testing history weakened the association between awareness of the 'I Did It' advertisement and HIV testing further (rate ratio 1.16, $95 \%$ CI 0.92 to $1.46, p=0.22$ ). After full adjustment, the average monthly casual partners and the most recent test before the survey both retain a strong association with rate of testing during the survey period, but the associations with age group, SHA of residence and relationship status were weakened $(\mathrm{p}=0.02,0.32$ and 0.38 , respectively, table 4$)$.

Awareness of the 'Clever Dick/Smart Arse' advertisement was not associated with rates of testing (rate ratio $1.18,95 \%$ CI 0.96 to $1.44, p=0.11)$. Restricting analysis to the time period when the advertisement was implemented results in a weak unadjusted association (rate ratio $1.28,95 \%$ CI 0.98 to $1.67, \mathrm{p}=0.07$ ). Participants reporting awareness of 'Count Me In' had an unadjusted rate of HIV testing during the study which was $17 \%-75 \%$ greater than those with no awareness of it (rate ratio 1.43, 95\% CI 1.17 to $1.75, p=0.0006)$. The rate of HIV testing did not significantly vary across the three periods of the year examined $(p=0.21)$.

The strength of the association between awareness of the 'I Did It' advertisement and rate of testing was further weakened by the addition to the model of these exposures to other health promotion interventions (rate ratio $1.11,95 \%$ CI 0.85 to 1.45 , $\mathrm{p}=0.45$, table 3 ). In the fully adjusted model, the associations of rates of testing with 'Clever Dick/Smart Arse' and period of the year were further weakened, as was the association with the 'Count Me In' intervention which ceased to be significant $(p=0.50$, table 4$)$. The associations between age group, SHA of residence and relationship status were also further weakened in this group. However, monthly average sexual partners and most recent HIV test both remained strongly associated with rates of testing during the survey period.

Table 3 Associations between the 'I Did It' print advertisement and rates of HIV testing, adjusted for significant sociodemographic characteristics, and exposures measured at each subgroup

\begin{tabular}{|c|c|c|c|c|c|c|}
\hline & $\begin{array}{l}\text { No } \\
\text { men }\end{array}$ & $\begin{array}{l}\% \\
\text { men }\end{array}$ & Unadjusted & $\begin{array}{l}\text { Adjusted for } \\
\text { significant } \\
\text { sociodemographic } \\
\text { characteristics* } \\
(95 \% \mathrm{Cl})\end{array}$ & $\begin{array}{l}\text { Adjusted for significant } \\
\text { sociodemographic } \\
\text { characteristics } \\
\text { and those in subgroup } \\
2+(95 \% \mathrm{Cl})\end{array}$ & $\begin{array}{l}\text { Adjusted for significant } \\
\text { sociodemographic } \\
\text { characteristics and those } \\
\text { in subgroups } 2 \text { and } 3 \ddagger \\
(95 \% \mathrm{Cl})\end{array}$ \\
\hline Subgroup 1: $n=1122 \S$ & & & $p=0.03$ & $p=0.08$ & - & - \\
\hline Not seen advertisement & 1036 & 92.3 & Ref & Ref & - & - \\
\hline $\begin{array}{l}\text { Recognised, or had seen } \& \text { read } \\
\text { advertisement }\end{array}$ & 86 & 7.7 & $\begin{array}{l}1.37(1.03 \text { to } \\
1.81)\end{array}$ & $1.29(0.97$ to 1.70$)$ & - & - \\
\hline Subgroup 2: $\mathrm{n}=879 \S$ & & & $p=0.04$ & $p=0.15$ & $p=0.22$ & - \\
\hline Not seen advertisement & 806 & 91.7 & Ref & Ref & Ref & - \\
\hline $\begin{array}{l}\text { Recognised, or had seen \& read } \\
\text { advertisement }\end{array}$ & 73 & 8.3 & $\begin{array}{l}1.38(1.02 \text { to } \\
1.86)\end{array}$ & $1.24(0.92$ to 1.67$)$ & $1.16(0.92$ to 1.46$)$ & - \\
\hline Subgroup 3: $n=719$ & & & $p=0.02$ & $p=0.09$ & $p=0.27$ & $p=0.45$ \\
\hline Not seen advertisement & 663 & 92.2 & Ref & Ref & Ref & Ref \\
\hline $\begin{array}{l}\text { Recognised, or had seen \& read } \\
\text { advertisement }\end{array}$ & 56 & 7.8 & $\begin{array}{l}1.48(1.06 \text { to } \\
2.06)\end{array}$ & $1.33(0.96$ to 1.85$)$ & $1.16(0.90$ to 1.50$)$ & $1.11(0.85$ to 1.45$)$ \\
\hline
\end{tabular}


Table 4 Adjusted rate ratios for all included exposures, for each sub-group

\begin{tabular}{|c|c|c|c|c|}
\hline Exposure & Main sample ( $n=1966)$ & Subgroup $1(n=1122)$ & Subgroup $2(n=879)$ & Subgroup $3(n=719)$ \\
\hline Age group (years) & $p=0.06$ & $p=0.005$ & $p=0.02$ & $p=0.13$ \\
\hline$<25$ & Ref & Ref & Ref & Ref \\
\hline $25-34$ & $1.42(1.02$ to 1.97$)$ & $1.21(0.85$ to 1.72$)$ & $1.07(0.77$ to 1.50$)$ & $1.05(0.70$ to 1.55$)$ \\
\hline $35-44$ & $1.18(0.84$ to 1.66$)$ & 0.95 (0.67 to 1.33$)$ & 0.89 (0.63 to 1.24$)$ & 0.86 (0.58 to 1.27$)$ \\
\hline $45-54$ & $1.16(0.82$ to 1.64$)$ & 0.87 (0.62 to 1.23$)$ & 0.82 (0.58 to 1.14$)$ & 0.83 (0.56 to 1.22$)$ \\
\hline $55+$ & $1.02(0.69$ to 1.50$)$ & $0.73(0.50$ to 1.05$)$ & 0.71 (0.49 to 1.02$)$ & $0.73(0.48$ to 1.12$)$ \\
\hline SHA of residence & $\mathrm{p}=0.01$ & $\mathrm{p}=0.0009$ & $\mathrm{p}=0.32$ & $p=0.45$ \\
\hline London & Ref & Ref & Ref & Ref \\
\hline South West & $0.84(0.65$ to 1.10$)$ & $0.82(0.61$ to 1.09$)$ & $0.92(0.71$ to 1.20$)$ & 0.91 (0.68 to 1.22$)$ \\
\hline South Central & $0.79(0.58$ to 1.06$)$ & $0.62(0.44$ to 0.86$)$ & 0.84 (0.61 to 1.16$)$ & 0.91 (0.66 to 1.27$)$ \\
\hline South East Coast & 0.66 (0.50 to 0.87$)$ & $0.70(0.52$ to 0.95$)$ & 0.83 (0.63 to 1.09 ) & $0.82(0.61$ to 1.10$)$ \\
\hline East of England & 0.83 (0.63 to 1.11$)$ & 0.92 (0.67 to 1.25$)$ & 1.22 (0.93 to 1.59$)$ & $1.26(0.92$ to 1.74$)$ \\
\hline East Midlands & 0.56 (0.40 to 0.78$)$ & $0.50(0.34$ to 0.73$)$ & $0.88(0.62$ to 1.25$)$ & 0.89 (0.60 to 1.32$)$ \\
\hline West Midlands & $0.68(0.49$ to 0.93$)$ & 0.57 (0.39 to 0.84$)$ & 0.78 (0.54 to 1.11$)$ & 0.75 (0.50 to 1.12$)$ \\
\hline Yorkshire \& Humber & $0.70(0.51$ to 0.95$)$ & $0.72(0.51$ to 1.03$)$ & $0.95(0.67$ to 1.36$)$ & $0.92(0.63$ to 1.34$)$ \\
\hline North West & $0.89(0.69$ to 1.14$)$ & $0.96(0.74$ to 1.26$)$ & $1.14(0.89$ to 1.46$)$ & $1.12(0.86$ to 1.47$)$ \\
\hline North East & 0.77 (0.50 to 1.18$)$ & $0.67(0.41$ to 1.10$)$ & 0.89 (0.56 to 1.42$)$ & $0.88(0.52$ to 1.47$)$ \\
\hline Relationship status & $p=0.03$ & $p=0.03$ & $\mathrm{p}=0.38$ & $p=0.70$ \\
\hline Single & Ref & Ref & Ref & Ref \\
\hline With one man only & $0.81(0.65$ to 1.01$)$ & $0.79(0.67$ to 0.93$)$ & 0.93 (0.79 to 1.08$)$ & $0.96(0.81$ to 1.13$)$ \\
\hline With $2+$ men but no women & $1.36(0.93$ to 1.99$)$ & $1.17(0.77$ to 1.78$)$ & $1.04(0.74$ to 1.46$)$ & $1.02(0.70$ to 1.47$)$ \\
\hline With one or more women & $0.89(0.60$ to 1.31$)$ & $1.02(0.69$ to 1.52$)$ & $1.27(0.88$ to 1.84$)$ & $1.24(0.82$ to 1.87$)$ \\
\hline 'I Did It' press advertisement & & $\mathrm{p}=0.08$ & $\mathrm{p}=0.22$ & $p=0.45$ \\
\hline Not seen advertisement & - & Ref & Ref & Ref \\
\hline Recognised, or had seen \& read, advertisement & - & $1.29(0.97$ to 1.70$)$ & $1.16(0.92$ to 1.46$)$ & $1.11(0.85$ to 1.45$)$ \\
\hline Lifetime sexual partners & & & $\mathrm{p}=0.32$ & $p=0.27$ \\
\hline$\leq 20$ & - & - & Ref & Ref \\
\hline $21-50$ & - & - & $0.92(0.71$ to 1.17$)$ & $0.84(0.64$ to 1.11$)$ \\
\hline $51-100$ & - & - & 0.85 (0.66 to 1.11$)$ & $0.82(0.62$ to 1.10$)$ \\
\hline $101-250$ & - & - & $0.91(0.69$ to 1.19$)$ & $0.85(0.63$ to 1.15$)$ \\
\hline $251-500$ & - & - & $0.72(0.54$ to 0.96$)$ & $0.68(0.49$ to 0.92$)$ \\
\hline $500+$ & - & - & $0.87(0.65$ to 1.17$)$ & $0.83(0.60$ to 1.15$)$ \\
\hline Monthly average casual sexual partners & & & $p<0.0001$ & $p<0.0001$ \\
\hline$<1$ & - & - & Ref & Ref \\
\hline $1-2$ & - & - & $1.40(1.16$ to 1.70$)$ & $1.45(1.17$ to 1.80$)$ \\
\hline$>2$ & - & - & $1.77(1.42$ to 2.20$)$ & 1.84 (1.44 to 2.34$)$ \\
\hline Last HIV test before survey enrolment & & & $p<0.0001$ & $p<0.0001$ \\
\hline Never tested & - & - & Ref & Ref \\
\hline$>12$ months before enrolment & - & - & $1.46(1.04$ to 2.05$)$ & $1.44(1.00$ to 2.07$)$ \\
\hline $6-12$ months before enrolment & - & - & 2.84 (2.03 to 3.97$)$ & 2.56 (1.77 to 3.68$)$ \\
\hline $1-6$ months before enrolment & - & - & 3.83 (2.84 to 5.17$)$ & $3.71(2.67$ to 5.15$)$ \\
\hline$<1$ month before enrolment & - & - & 7.75 (5.70 to 10.55$)$ & 7.24 (5.17 to 10.15$)$ \\
\hline 'Clever Dick/Smart Arse' press advertisements & & & & $\mathrm{p}=0.52$ \\
\hline No awareness of advertisements & - & - & - & Ref \\
\hline Any awareness of advertisements & - & - & - & $1.06(0.89$ to 1.26$)$ \\
\hline 'Count Me In' intervention & & & & $p=0.50$ \\
\hline No awareness of intervention & - & - & - & Ref \\
\hline Any awareness of intervention & - & - & - & $1.06(0.89$ to 1.27$)$ \\
\hline Time period of testing & & & & $p=0.25$ \\
\hline 1 January 2011-30 April 2011 & - & - & - & Ref \\
\hline 1 May 2011-30 September 2011 & - & - & - & $0.94(0.80$ to 1.11$)$ \\
\hline 1 October 2011-31 January 2013 & - & - & - & $1.08(0.92$ to 1.27$)$ \\
\hline
\end{tabular}

\section{DISCUSSION}

Rates of HIV testing among these participants was more than one test per year, higher than the UK national guidelines minimum for HIV testing. ${ }^{5}$ However, HIV testing was strongly clustered, with some men reporting 10 tests and others none. A recent test prior to the study entry was the strongest predictor of testing. Average monthly casual sex partners was more strongly associated with testing than sociodemographic factors 
or lifetime sexual partners. This suggests that men with many partners are more aware of the need to test regularly.

Lower rates of HIV testing were observed among older men, men in relationships and those with fewer sexual partners, patterns seen in other countries including Scotland ${ }^{10}$ and Australia. ${ }^{11}$ In this 2011 survey in England, testing appeared particularly low in the East Midlands.

Recognition of the 'I Did It' intervention was very low and less than the other two interventions, and most other similar previous interventions by the same provider. ${ }^{12-14}$ 'I Did It' had a significant unadjusted association with HIV testing which reduced on adjusting for sociodemographic factors and reduced further on adjusting for casual sexual partners. It is possible that our sample was generally already aware of HIV testing issues and more likely to recognise a testing campaign, but would have tested anyway. There was no overall effect of time period on rates of testing, nor did time period act as an effect modifier in the unadjusted association between 'I Did It' and testing.

There have been few longitudinal studies of HIV testing among MSM in England and these are now very dated. ${ }^{15} 16$ The majority of data on HIV testing among MSM come from cross-sectional surveys using retrospective recall. This is the first UK study that has attempted to reduce recall bias of HIV risk and precautionary behaviours by monthly questioning. It is likely that participation in our study with regular questioning about HIV testing behaviour influenced at least some men's propensity to test. However, $82 \%$ of participants had already had at least one test before joining the study, and of the men who were untested at enrolment, $80 \%$ remained untested.

Our results should be interpreted with caution for several reasons. First, ours was a non-experimental study: men were not allocated randomly or otherwise to be exposed to interventions, but rather we examined associations between individuals' selfreported recognition of interventions and subsequent testing. It may be that those who recognised the 'I Did It' intervention differed in important, unmeasured ways from those who did not. However, we strove to measure and adjust for potential confounders including self-reported exposure to other HIV health promotion interventions. Through this we showed that 'I Did It' had a significant unadjusted association with HIV testing which disappeared when adjusting for socioeconomic factors and reduced further when adjusting for current sexual behaviour. Second, despite our regular data collection, recall error may have been systematically related to individuals' testing patterns, introducing the possibility of information bias. Finally, our sample was

\section{Key messages}

- Recruitment and retention of men who have sex with men (MSM) to an online panel for monthly surveying is feasible and acceptable.

- Although, collectively, MSM in this study took more than one test per year per person, testing was highly clustered and most men did not test in the year period.

- HIV testing is strongly associated with numbers of casual sexual partners, suggesting testing is more common among men at greater risk of HIV/STIs.

- A national social marketing intervention aimed at increasing testing among MSM was seen by a small proportion of the target group and did not appear to increase testing in those exposed to it. selective, both by its being an online convenience sample, as discussed in our introduction, ${ }^{6}$ and by the large proportion of study members who were excluded from our analysis because they did not provide sufficient data across key time-points.

Our findings suggest a need for HIV testing promotion interventions to achieve much higher coverage and impact than that investigated in this study. Previous research suggests that this media intervention achieved particularly low recall.

\section{Handling editor Jackie A Cassell}

Acknowledgements Our thanks go to Richard Scholey (THT), Matthew Hodson (GMFA), Bobby Pickering (Demographix), David Novak (Online Buddies Inc.) and all the men who took part in the Sigma Panel 2011.

Contributors PW conceived the Sigma panel and its technical specification. $\mathrm{FH}$ coordinated the panel study. FH, CB and DR designed the monthly questionnaires. $\mathrm{DR}$ and FH were responsible for communications with respondents, the technical implementation of the panel and data management and cleaning. $\mathrm{KT}, \mathrm{FH}, \mathrm{CB}$ and $\mathrm{JH}$ planned the data analysis. KT performed the data analysis. $\mathrm{FH}$ and $\mathrm{KT}$ drafted the paper and PW, JH and CB edited it. All authors contributed to and agreed the final manuscript.

Funding This work was supported by the Department of Health for England through the CHAPS programme.

\section{Competing interests None.}

Ethics approval London School of Hygiene and Tropical Medicine Ethics Committee (approval number 5834).

Provenance and peer review Not commissioned; externally peer reviewed.

Data sharing statement No additional unpublished data from this study are currently available as analysis by the investigators is ongoing.

\section{REFERENCES}

1 Marks G, Crepaz N, Senterfitt W, et al. Meta-analysis of high-risk sexual behavior in persons aware and unaware they are infected with HIV in the United States: implications for HIV prevention programs. JAIDS 2005;39:446-53.

2 The EMIS Network. EMIS 2010: the European men-who-have-sex-with-men internet survey. Findings from 38 countries. Stockholm: European Centre for Disease Prevention and Control, 2013

3 Health Protection Agency. HIV in the United Kingdom: 2012 Report. Colindale: Health Protection Services, 2012.

4 Lorenc T, Marrero-Guillamón I, Aggleton P. Promoting the uptake of HIV testing among men who have sex with men: systematic review of effectiveness and cost-effectiveness. Sex Trans Infect 2011;87:272-8.

5 British HIV Association. UK National Guidelines for HIV Testing 2008. London: BHIVA, 2008

6 Evans AR, Wiggins RD, Mercer $\mathrm{CH}$, et al. Men who have sex with men in Great Britain: comparison of a self-selected internet sample with a national probability sample. Sex Transm Infect 2007;83:500

7 Elford J, Doerner R, McKeown E, et al. HIV Infection among ethnic minority and migrant men who have sex with men in Britain. Sex Transm Dis 2008;39:678-86.

8 Hickson F, Bonell C, Hargreaves J, et al. HIV testing and HIV serostatus-specific sexua risk behaviour among men who have sex with men living in England and recruited through the internet in 2001 and 2008. Sex Res Soc Policy 2013;10:15-23.

9 Weatherburn P, Schmidt AJ, Hickson F, et al. The European Men-Who-Have-SexWith-Men Internet Survey (EMIS): Design and Methods. Sex ResSoc Policy 2013; 10:243-57

10 Knussen C, Flowers P, McDaid L. Factors associated with recency of HIV testing amongst men residing in Scotland who have sex with men. AIDS Care 2014;26:297-303.

11 Holt M, Rawstorne P, Wilkinson J, et al. HIV testing, gay community involvement and internet use: social and behavioural correlates of HIV testing among Australian men who have sex with men. AIDS Behav 2012;16:13-22.

12 Weatherburn P, Dodds C, Branigan P, et al. Successful measures: evaluation of CHAPS national HIV prevention campaigns targeted at gay men 2001 to 2003. London: Sigma Research, 2003.

13 Weatherburn P, Dodds C, Branigan P, et al. Form and Focus: evaluation of CHAPS national interventions 2003 to 2006. London: Sigma Research, 2007.

14 Weatherburn P, Henderson L, Reid D, et al. Advertising awareness: evaluation of CHAPS national HIV prevention adverts and leaflets targeted at gay men 1996 to 2000. London: Sigma Research, 2001.

15 Fitzpatrick R, Dawson J, Boulton M, et al. Social psychological factors that may predict high risk sexual behaviour in gay men. Health Educ J 1991;50:63-6.

16 Hunt AJ, Davies PM, McManus TJ, et al. HIV infection in a cohort of homosexual and bisexual men. BMJ.1992:305:561-2. 